\title{
Polyacrylamide application for dewatering of clay slimes from halurgy plants by centrifugation
}

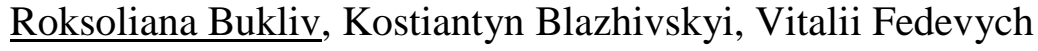 \\ Department of Chemistry and Technology of Inorganic Substances, Lviv Polytechnic National University, \\ 12 Bandera street, Lviv, Ukraine, 79013 E-mail: roksolyanabukliv@gmail.com
}

\begin{abstract}
The influence of precipitation centrifugation on the dewatering efficiency of clay-salt sludges. The moisture content of the resulting sludge was found to be decreased in proportion to the increase of the centrifuge separation factor. The addition of polyacrylamide solution to the suspension allows to reduce the moisture content of centrifuged sludge by $3 . . .4 \%$.
\end{abstract}

Keywords: clay sludge, precipitation centrifugation, polyacrylamide, humidity.

\section{Introduction}

Polymineral potassium ores of the Precarpathian region, Ukraine, are characterized by a high content of clay impurities, which reaches $20 . . .25 \%$ by weight. Ores processing is accompanied by the formation of clay-salt sludges, with which the useful ore components are lost. The existing technology includes three-stage washing of sludge with settling, which is ineffective and complicates the technological process. The washed sludge has high humidity and salt content. To intensify the process and minimize the content of washing solution in the final sludge, it is advisable to apply a centrifugation method.

\section{Experimental part}

Polymineral potassium ore (Stebnitsky deposit, Ukraine) with $12.3 \%$ of clay impurities was used in this research. It was dissolved in water and saturated solution was separated with decanting of clay sludge. The sludge was homogenized and centrifuged on laboratory centrifuges of precipitating type. The influence of the centrifuge separation factor (in the range of $1160 \ldots 8700$ ) and the centrifugation time on the moisture content was investigated in a centrifuged precipitate. To intensify the precipitation $0.25 \%$ solution of polyacrylamide was added as a flocculant. The experiments were carried out both with and without it. The moisture content in the sludge was determined by its drying at $105 \ldots 110{ }^{\circ} \mathrm{C}$ till the weight became constant. The centrifugation efficiency was evaluated relative to the moisture content in the final sludge (wt. \%).

The research results showed that at the same centrifugation time (5 minutes), the moisture content of centrifuged sludges varied from 33 to $28 \%$ with an increase in the separation factor in the investigated range according to the dependence close to the proportional one. After the flocculant addition to the suspension, some aggregation of clay particles occurred, resulting in the decrease of centrifuged sludge moisture content by $3 . . .4 \%$ compared with the previous experiments. At the same time, the higher the separation factor, the more significant reduction. Recentrifugation of the sludge provided the reduction of moisture content by another $3 \%$, indicating the ability of the sludge to be compressed.

\section{Conclusions}

For the dewatering of clay sludge from halurgy plants, it is advisable to use the precipitation centrifugation method, which makes it possible to intensify and simplify the technology. Adding the polyacrylamide to the initial suspension helps to reduce the final moisture content by $3 \ldots 4 \%$. 